\title{
APLICABILIDADE DA PRISÃO DOMICILIAR
}

\author{
Ana Valeska Souza Bittencourt Lussari
}

Universidade do Oeste Paulista - UNOESTE, curso de Direito, Presidente Prudente, SP. E-mail: valeskalussari2011@gmail.com

\section{RESUMO}

O objetivo deste estudo foi levantar as particularidades da prisão domiciliar, tendo em vista que no último ano, a incidência de utilização da mesma tem ocorrido de maneira mais constante como alternativa de cumprimento de pena em regime aberto.

Esta modalidade de prisão está disciplinada no artigo 318 do código de Processo Penal, que traz os pressupostos necessários para que o juiz possa avaliar a viabilidade e o enquadramento da medida ao caso concreto. Tem carácter de medida provisória, processual e cautelar com a finalidade e a capacidade de substituir a prisão preventiva.

Esta pesquisa destaca os principais pontos desta modalidade de pena a fim de esclarecer sua aplicabilidade e qual o atual entendimento jurisprudencial para sua aplicabilidade.

Após realizar pesquisa bibliográfica fica constatado que há muito a se evoluir e a se aprofundar no referido assunto e que realmente além das funções referentes a pena, existe também uma questão moral e social em torno desta modalidade de pena, que além de ser uma medida cautelar e punitiva, envolve políticas públicas e o Estatuto da primeira infância.

Palavras-chave: Prisão domiciliar, Prisão Preventiva, Pena e Direitos.

\section{APPICABILITY OF DOMICILIARY PRISON}

\begin{abstract}
The objective of this study was to raise the particularities of house arrest, considering that in the last year, the incidence of the use of the same has occurred more consistently as an alternative to comply with the sentence in open regime.

This type of arrest is regulated by Article 318 of the Code of Criminal Procedure, which provides the necessary conditions for the judge to assess the feasibility and the framework of the measure in the specific case. It has the character of a provisional, procedural and precautionary measure with the purpose and the capacity to replace the preventive prison.

This research highlights the main points of this modality of pen in order to clarify its applicability and what the current jurisprudential understanding for its applicability.

After carrying out a bibliographical research, it is verified that there is a lot to be developed and deepened in the mentioned subject and that really beyond the functions related to the sentence, there is also a moral and social question around this type of sentence, which besides being a precautionary measure And punitive, involves public policies and the Statute of early childhood.
\end{abstract}

Keywords: House arrest, Preventive Detention, Penalty and Rights.

\section{INTRODUÇÃO}

A prisão domiciliar tem sido amplamente citada nos últimos noticiários tendo em vista a grande repercussão das investigações envolvendo políticos e crimes de corrupção, onde esta medida cautelar acabou sendo um meio de cumprimento de pena e elemento de substituição à prisão preventiva em algumas situações onde a lei prevê esta alternativa. 
Na maioria das vezes pode ser considerada como um benefício ao preso, e está disciplinada nos artigos 317 e 318 do código de Processo Penal. Os incisos do art. 318 do CPP trazem os pressupostos necessários para que o juiz possa avaliar a viabilidade e o enquadramento da medida ao caso concreto.

A lei 13.257 de 2016 altera o art. 318 trazendo algumas novas possibilidades de concessão da prerrogativa de prisão domiciliar e ao contrário do que analisamos em um primeiro momento, as alterações não visam contemplar a pessoa sobre a qual recai a concessão. No que diz respeito aos incisos IV, V e VI do art. 318, observa-se que a redação da lei 13.257/16, estabelece políticas públicas para primeira infância, não se tratando de dar ou não uma concessão ao apenado, sendo que estes incisos possuem outro o foco.

Importante ressaltar que qualquer que seja a situação listada no art. 318, a pessoa presa preventivamente continuará presa, porém, em regime domiciliar, pois conforme determina o art. 317 CPP, deverá permanecer recolhida em sua residência em tempo integral, ou seja 24 horas por dia, e em caso de descumprimento injustificado desta condição, ocorrerá o retorno ao cárcere.

Ao contrário do que a maioria interpreta, a prisão domiciliar, não tem em seu escopo somente o fator "mérito" do apenado. Como dizer que uma pessoa presa para garantia da ordem pública, da ordem econômica, por conveniência da instrução criminal ou para assegurar a aplicação da lei penal (CPP, art.312, caput), desfruta de mérito, ou reúne atributos subjetivos positivos que possam ser valorados?

Este artigo tem como objetivo esclarecer a aplicabilidade da prisão domiciliar como substituta da prisão preventiva e em quais possibilidades isto será possível de acordo com o ordenamento jurídico e os julgados já formados.

\section{METODOLOGIA}

Segundo Gil (2012), a metodologia utilizada para pesquisa é bibliográfica, pois foi desenvolvida através de materiais já publicados. Conforme discorrido em sua publicação esta característica em seu aspecto técnico é bibliográfica, uma vez que a mesma é definida como sendo aquela que 'é desenvolvida com base em materiais já publicados. Engloba, leituras, analise, interpretações de livros, textos legais, documentos ou fotocópias, mapas, fotos e manuscritos. ' A metodologia utilizada para a pesquisa foi bibliográfica, uma vez que o artigo foi desenvolvido com base em materiais já publicados e as legislações em vigor.

Quanto aos Objetivos, a pesquisa caracteriza-se como exploratória, uma vez que segundo Gil (2009), os objetivos de uma pesquisa podem caracterizar-se como exploratória, quando traz como definição que a familiarização com um assunto pouco conhecido ou pouco explorado, para que no final da pesquisa possa se conhecer mais deste assunto, estando apto a formular hipóteses.

\section{RESULTADOS}

Considerando o introito deste artigo, verificou-se que a prisão domiciliar, foi reformulada e está prevista no ordenamento jurídico Brasileiro pela Lei $12.403 / 11$, como alternativa à prisão preventiva e está disciplinada no art. 317 do CPP, o qual discorre que ' a prisão domiciliar consiste no recolhimento do indiciado ou acusado em sua residência, só podendo dela ausentar-se com autorização judicial'.

É aplicada como forma alternativa de cumprimento de pena, devendo ser deferida nos casos onde estão presentes os requisitos para decretação de prisão preventiva, e em conjunto observados os pressupostos do art. 318 do CPP, sendo possível a modificação do sistema prisional carcerário para o de recolhimento domiciliar.

Eugenio Pacelli afirma que: 
Trata-se de prisão domiciliar, prevista no art. 317, CPP, que determina o recolhimento permanente do indiciado ou acusado em sua residência, dali não podendo ausentar-se senão por meio de autorização judicial expressa. " (Pacelli, Eugenio,2012).

Quanto ao cabimento da prisão domiciliar necessário se faz observar o que discorre o artigo 318 do Código de Processo penal e seus incisos, o que faremos a seguir.

Art. 318. Poderá o Juiz substituir a prisão preventiva pela domiciliar quando o agente for:

I- $\quad$ Maior de 80(oitenta) anos;

II- Extremamente debilitado por motivo de doença grave;

III- Imprescindível aos cuidados especiais de pessoa menos que 6(seis) anos de idade ou com deficiência;

IV- Gestante;

V- $\quad$ Mulher com filho de até 12(doze) anos de idade incompletos;

VI- Homem, caso seja o único responsável pelos cuidados do filho de até 12(doze) anos de idade incompletos.

Parágrafo único: Para substituição, o juiz exigirá prova idônea dos requisitos estabelecidos neste artigo.

A lei 12.403/2011 que regulava até então o referido dispositivo, foi alterada em 2016 pela lei 13.257/2016 em seus incisos IV, V e VI. Neste ponto, importante ressaltar que estas alterações não tem o objetivo de estender as possibilidades do apenado em relação ao regime prisional e que seu foco está mais ligado as políticas públicas para primeira infância, no denominado Estatuto da Primeira infância, e é aqui que se encontra a verdadeira e adequada compreensão da questão.

É necessário detalhar as principais alterações ocorridas nestes incisos através da lei 13.257/2016, para melhor compreensão da afirmação acima.

No que se refere a gestante, antes da vigência da referida lei, o inc. IV do 318 do CPP trazia a previsão de reversão de pena em domiciliar somente a partir do sétimo mês de gravidez, ou gestação, a qualquer tempo, de alto risco. Atualmente o dispositivo refere-se apenas à gestante, podendo a substituição da prisão preventiva por domiciliar, ser requerida apenas com a comprovação do estado gestacional, em qualquer estágio e independente da possibilidade de risco.

Neste item pode-se observar que a cautela se refere ao nascituro e não a gestante, e mesmo que fosse diferente, é forçoso concluir que a situação em que a mulher se encontra refletirá no desenvolvimento do feto e ainda, que nosso sistema prisional atualmente não tem a mínima possibilidade de assegurar o cumprimento destacado na LEP em seu $\S 3$ odo art. 14, que assegura o acompanhamento médico à mulher, principalmente no pré-natal e no pós-parto, extensivo ao recém-nascido.

$\mathrm{O}$ inc. $\mathrm{V}$ do art.318 do CPP, foi introduzido pela lei 13.257/16 e dispões diretamente sobre políticas públicas para a primeira infância. A proteção neste caso, recai especificamente sobre quem seja filho de mulher presa preventivamente, sendo que para obter a substituição é necessário que a mulher apenada tenha filho menor de 12 (doze) anos de idade e que por ocasião da custódia cautelar, a criança se encontre sob os cuidados e responsabilidade de sua genitora que foi presa preventivamente.

Em casos em que a criança já esteja aos cuidados de outrem, não há sentido em conceder a substituição por falta de fundamento ético que motiva a política protetiva da primeira infância, aqui pretendida pelo legislador. 
O ordenamento visa instituir benefício em prol do filho de até 12 (doze) anos e não a substituição da forma de cumprimento da pena de maneira injustificada para as genitoras.

Já o inciso VI, do artigo 318 do CPP, é expresso ao restringir sua aplicabilidade ao homem e só terá cabimento se em razão da custódia do genitor, o filho de até 12(doze) anos ficar em completo desamparo. Se na ocasião, o filho já se encontrasse sob os cuidados de terceiro, a substituição não será permitida, visto que a disposição jurídica, não visa permitir a utilização da prole como salvo-conduto.

\section{DISCUSSÃO}

Quanto a aplicabilidade e os requisitos deste artigo temos ainda que destacar o entendimento jurisprudencial acerca do assunto, principalmente na polemica questão quanto a interpretação da palavra "poderá" constante no art. 318 do CPP, caput.

Há interpretações no sentido de que está palavra (poderá) deve ser entendida como imperativa, ou seja, todas as vezes que o preso se enquadrar em uma das situações previstas nos incisos deste artigo, o juiz obrigatoriamente teria que reverter a prisão preventiva em prisão domiciliar.

Neste quesito, tem ficado pacificado que o juiz deve avaliar todos os aspectos de ordem subjetiva que estejam de alguma forma relacionados ao caso concreto, e só após, deferir ou não a substituição.

A posição dos autores Eugênio Pacelli e Douglas Fischer (2012, p. 645-646) e de Norberto Avena (2013, p. 487), é de que sempre será necessário analisar as demais circunstâncias do caso concreto para se definir se a prisão domiciliar é viável e suficiente.

Conforme jurisprudência, este entendimento quanto a necessidade de adequação e analise do juiz ao caso concreto tem se confirmado, verifica-se este fato no despacho proferido pelo rel. Min. Antonio Saldanha Palheiro que discorre de forma simples e clara a contextualização aqui configurada: "Não obstante as alterações havidas no Código de Processo Penal pelo Estatuto da Primeira Infância (lei 13.257/16), e o munus do Estado no 'fortalecimento da família no exercício de sua função de cuidado e educação de seus filhos na primeira infância' (art. 14, $\S 10$ ), certo é que a jurisprudência desta Corte Superior firmou-se no sentido de que não se trata de 'dever' do julgador a determinação do cumprimento da prisão preventiva em custódia domiciliar quando se verificarem as condições objetivas previstas em lei. Posto isso, o verbo 'poderá' constante do caput do art. 318 da lei adjetiva criminal não há de ser interpretado como uma obrigação judicial, sob pena de se extrair do magistrado a possibilidade de decidir de acordo com as peculiaridades concretas. Desse modo, nem toda pessoa com prole na idade indicada pelo dispositivo legal terá direito à cautela domiciliar, caso a medida não seja demonstrada como única providência cabível ao desenvolvimento infantil apropriado (Precedentes)" (STJ, RHC 74.933/MT, 6ạ T., rel. Min. Antonio Saldanha Palheiro, j. 18-10-2016, DJe de 10-11-2016).

Nessa mesma linha de pensamento: STJ, RHC 73.914/SP, 5a T., rel. Min. Felix Fischer, j. 20-10-2016, DJe de 21-11-2016; STJ, RHC 71.697/SP, 5a T., rel. Min. Joel Ilan Paciornik, j. 17-112016, DJe de 23-11-2016; STJ, RHC 73.399/RJ, 6a T., rel. Min. Nefi Cordeiro, j. 23-8-2016, DJe de 1-9-2016.

Mediante a estes julgados é preciso considerar que as condições descritas no artigo 318 do CPP, são alguns exemplos, não impedindo o juiz de analisar os fatores subjetivos que envolvem a questão que o levaram ao convencimento de conceder ou não, a reversão da prisão preventiva em prisão domiciliar.

Se achar necessário, o juiz pode ainda, impor condições adicionais para atender a prerrogativa da reversão, como por exemplo o monitoramento eletrônico, que visa identificar se o 
condenado realmente está obedecendo a restrição judicial imputada, sob pena de volta ao cárcere em caso de desobediência.

\section{CONCLUSÃO}

Trata-se de legislação que sofreu alterações recentemente (2016), onde o entendimento jurisprudencial quanto a questão ainda está em fase de pacificação. Constata-se que as alterações realizadas no ano de 2016, vieram de encontro com a nova realidade social, trazendo uma preocupação que vai além da punição e abrangendo o campo social, quando se integra ao ordenamento penal características que vão além da relação crime e punição, e alcança o contexto social buscado pelo Estado, no sentido do indivíduo como um todo, prevendo inclusive o impacto desta medida cautelar na gestação, ao nascituro e aos filhos que fazem parte da primeira infância.

Revela ainda, uma responsabilidade adicional aos Magistrados, uma vez que tem se considerado relevante a analise subjetiva do juiz no caso concreto, não se atendo somente a letra fria da lei.

\section{REFERÊNCIAS}

AVENA, Norberto. Processo Penal. 7ạ ed., São Paulo. Método, p. 487.

GIL. Antonio Carlos. Métodos e Técnicas de Pesquisa Social. 6ạ Ed. São Paulo. Atlas S.A. 2012.

PACELLI, Eugênio. Curso de Processo Penal, 16ạ Edição, Editora Atlas. Pg. 563.

PACELLI, Eugênio e FISCHER, Douglas. Comentários ao Código de Processo Penal e sua jurisprudência. 4a ed., São Paulo. Atlas S.A, 2012, p.645-646.

http://www.ambito-juridico.com.br/site/?artigo id=10754\&n link=revista artigos leitura https://brasil.mylex.net/legislacao/codigo-processo-penal-cpp-art317 25421.html https://www.jusbrasil.com.br/jurisprudencia https://draflaviaortega.jusbrasil.com.br/noticias 